\title{
Long-term response to hormone therapy in a young woman with aggressive pelvic angiomyxoma
}

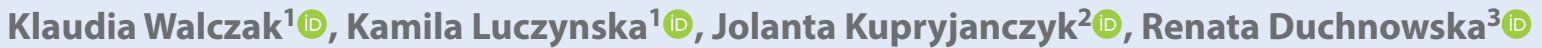 \\ ${ }^{1}$ Student Scientific Circle "Spero", Department of Oncology, Military Institute of Medicine, Warsaw, Poland \\ ${ }^{2}$ Department of Pathology National Cancer Institute, Warsaw, Poland \\ ${ }^{3}$ Department of Oncology, Military Institute of Medicine, Warsaw, Poland
}

Key words: aggressive angiomyxoma; antiestrogen therapy; pelvic tumor

A 39-year-old woman initially presented in May 2014 after transrectal core needle biopsy of the pelvic tumor. Pathology examination showed a spindle shaped cells within a predominantly myxoid richly vascularized stroma, nuclear atypia and low mitotic activity. Another tumor fragment included some adipose tissue and some thick bundles of smooth muscle. The tumor was diagnosed as an aggressive angiomyxoma (AAM) based on the positive staining with desmin, CD34, estrogen receptor and some convincing positive nuclear staining for HMGA2, especially in the more myxoid component. A diagnostic magnetic resonance imaging (MRI showed a huge mass in the retroperitoneal space (size $113 \times 65 \times 130 \mathrm{~mm}$; volume $300 \mathrm{~cm}^{3}$ ) with tissue adhesion to the anal muscle levator on the right side and to the vaginal vestibule wall (with possible infiltration) (Fig. $1 \mathrm{~A})$. The tissue filled the space behind the right part of the pubic symphysis and shaped the urinary bladder. The case was presented at sarcoma tumor board and was deemed to be unresectable. Based on literature review, the patient was administered subcutaneous gonadotropin-releasing hormone agonist (LHRH) in a dose of $3.6 \mathrm{mg}$ every month. After 3 months of LHRH therapy, MRI showed a marked partial tumor regression, although the lesion still adhered and connected to the right leg of the clitoris, the vaginal wall and anal muscle levator on the right side (size $47 \times 30 \times 50 \mathrm{~mm}$; volume $40 \mathrm{~cm}^{3}$ ) (Fig. 1B). After another 3 months the tumor has doubled compared to the best response (size $90 \times 40 \times 85 \mathrm{~mm}$; volume $115 \mathrm{~cm}^{3}$ ). The pressure on adjacent structures increased and there was greater displacement of the rectum to the left. Additionally, there was more pronounced adhesion to the right muscle of the internal veil and filling of the space behind the shaft of the right pubic bone. The decision was made to continue with an off-label combination of LHRH and tamoxifen ( $20 \mathrm{mg}$ daily). After 2 months, the control MRI showed partial regression (size $70 \times 37 \times 55 \mathrm{~mm}$; volume $50 \mathrm{~cm}^{3}$ ) (Fig. 1C). She has been continuing therapy for 6 years with good tolerance and response. AAM is a rare locally infiltrative mesenchymal tumor affecting young women and less frequently men [1, 2]. AAM usually develops in the perineal and pelvic regions. Most of AAMs show estrogen and progesterone receptor positivity and are likely to be hormone-dependent, although clinical data on sequential hormone therapy are scarce and mostly obtained from case reports [2-5]. The majority of cases concerned LHRH therapy before or after surgery, and demonstrated improving disease control with this approach [2-4, 6-14]. In a few cases, anti-estrogen therapy with tamoxifen, raloxifene or an aromatase inhibitor with LHRH showed activity in first or second-line treatment [11, 15-17].

A.

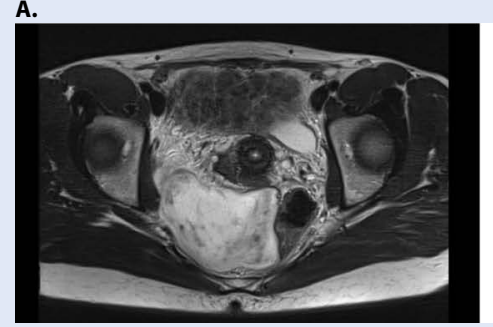

B.

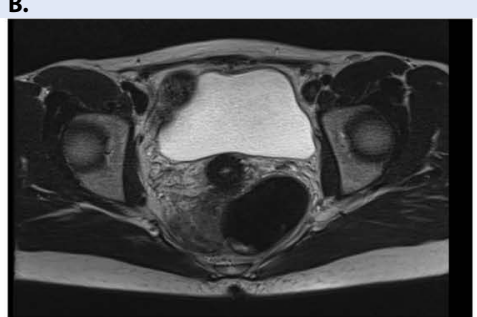

c.

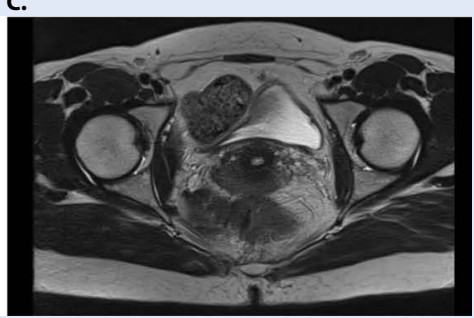

Figure 1. MRI of the pelvis, imaging sequences after administration of Gadovist $5 \mathrm{~mL}$ Siemens Magnetom Avanto 1.5 T contrast; A. At the diagnosis; B. After 3 months LHRH therapy; C. After 2 months LHRH and tamoxifen therapy 
In conclusion, off-label drug use is an opportunity for patients for whom formally approved therapy options have been exhausted or do not exist. Our study highlights the importance of sequential anti-estrogen hormone therapy, which may prove as an effective therapy in patients with hormone receptor positive AAMs. Lifetime follow-up to monitor for progression is mandatory.

\section{REFERENCES}

1. Chen $\mathrm{H}, \mathrm{Zhao} \mathrm{H}$, Xie Y, et al. Clinicopathological features and differential diagnosis of aggressive angiomyxoma of the female pelvis: 5 case reports and literature review. Medicine (Baltimore). 2017; 96(20): e6820, doi: 10.1097/MD.0000000000006820, indexed in Pubmed: 28514296.

2. Sun Y, Zhu L, Chang X, et al. Clinicopathological Features and Treatment Analysis of Rare Aggressive Angiomyxoma of the Female Pelvis and Perineum - a Retrospective Study. Pathol Oncol Res. 2017; 23(1): 131-137, doi: 10.1007/s12253-016-0109-y, indexed in Pubmed: 27571990.

3. Haldar K, Martinek IE, Kehoe S. Aggressive angiomyxoma: a case series and literature review. Eur J Surg Oncol. 2010; 36(4): 335-339, doi: 10.1016/j. ejso.2009.11.006, indexed in Pubmed: 19954923.

4. Schwartz PE, Hui P, McCarthy S. Hormonal therapy for aggressive angiomyxoma: a case report and proposed management algorithm. J Low Genit Tract Dis. 2014; 18(2): E55-E61, doi: 10.1097/LGT.0b013e3182a22019, indexed in Pubmed: 24402356.

5. Hajjar R, Alharthi M, Richard C, et al. Pelvic Aggressive Angiomyxoma: Major Challenges in Diagnosis and Treatment. Cureus. 2019; 11(4): e4419, doi: 10.7759/cureus.4419, indexed in Pubmed: 31245206.

6. Aguilar-Frasco J, Ruben-Castillo C, Rodríguez-Quintero JH, et al. Aggressive angiomyxoma: giant recurrence successfully treated with wide excision and adjuvant therapy with GnRH analogue. BMJ Case Rep. 2018; 11(1), doi: 10.1136/bcr-2018-226973, indexed in Pubmed: 30567120.

7. Alobaid A, Goffin F, Lussier C, et al. Aggressive Angiomyxoma of the Vulva or Perineum: Report of Three Patients. J Obstet Gynaecol Can. 2005; 27(11): 1023-1026, doi: 10.1016/s1701-2163(16)30501-1.

8. Aye $\mathrm{C}$, Jefferis $\mathrm{H}$, Chung DY, et al. A case of multi-modal managed vulval aggressive angiomyxoma diagnosed before conception and monitored during pregnancy. Gynecol Oncol. 2009; 115(1): 170-171, doi: 10.1016/j.ygyno.2009.05.035, indexed in Pubmed: 19560190.

9. Bai HM, Yang JX, Huang HF, et al. Individualized managing strategies of aggressive angiomyxoma of female genital tract and pelvis. Eur J Surg Oncol. 2013; 39(10): 1101-1108, doi: 10.1016/j.ejso.2013.06.013, indexed in Pubmed: 23899874.

10. Fine BA, Munoz AK, Litz CE, et al. Primary medical management of recurrent aggressive angiomyxoma of the vulva with a gonadotropin-releasing hormone agonist. Gynecol Oncol. 2001; 81(1): 120-122, doi: 10.1006/gyno.2000.6119, indexed in Pubmed: 11277663.

11. Fucà G, Hindi N, Ray-Coquard I, et al. Treatment Outcomes and Sensitivity to Hormone Therapy of Aggressive Angiomyxoma: A Multicenter, International, Retrospective Study. Oncologist. 2019; 24(7): e536-e541, doi: 10.1634/theoncologist.2018-0338, indexed in Pubmed: 30518617.

12. Im SW, Han SSu. Treatment of aggressive angiomyxoma of the female perineum: Combined operative and hormone therapy. J Obstet Gynaecol. 2016; 36(6): 819-821, doi: 10.3109/01443615.2016.1157151, indexed in Pubmed: 27146643

13. McCluggage WG, Jamieson T, Dobbs SP, et al. Aggressive angiomyxoma of the vulva: Dramatic response to gonadotropin-releasing hormone agonist therapy. Gynecol Oncol. 2006; 100(3): 623-625, doi: 10.1016/j.ygyno.2005.09.033, indexed in Pubmed: 16246403.

14. Palomba S, Oppedisano R, Annunziata G, et al. Leuprolide acetate depot plus high-dose raloxifene hydrochloride before and after surgery for recurrent vaginal aggressive angiomyxoma: a case report. Gynecol Oncol. 2011; 123(1): 172-173, doi: 10.1016/j.ygyno.2011.06.013, indexed in Pubmed: 21764109 .

15. Abu Jl, Bamford WM, Malin G, et al. Aggressive angiomyxoma of the perineum. Int J Gynecol Cancer. 2005; 15(6): 1097-1100, doi: 10.1111/j.1525-1438.2005.00182.x, indexed in Pubmed: 16343187.

16. Magtibay PM, Salmon Z, Keeney GL, et al. Aggressive angiomyxoma of the female pelvis and perineum: a case series. Int J Gynecol Cancer. 2006; 16(1): 396-401, doi: 10.1111/j.1525-1438.2006.00225.x, indexed in Pubmed: 16445665.

17. Giles DL, Liu PT, Lidner TK, et al. Treatment of aggressive angiomyxoma with aromatase inhibitor prior to surgical resection. Int J Gynecol Cancer. 2008; 18(2): 375-379, doi: 10.1111/j.1525-1438.2007.01005.x, indexed in Pubmed: 18334016. 